\title{
Experimental Investigation of a Rectangular Airlift Pump
}

\author{
I. I. Esen \\ Department of Civil Engineering, Kuwait University, P.O. Box 5969, Safat, Kuwait 13060, Kuwait \\ Correspondence should be addressed to I. I. Esen, ilkinesen@gmail.com
}

Received 25 September 2010; Accepted 6 December 2010

Academic Editor: Kirk Hatfield

Copyright ( 2010 I. I. Esen. This is an open access article distributed under the Creative Commons Attribution License, which permits unrestricted use, distribution, and reproduction in any medium, provided the original work is properly cited.

\begin{abstract}
Hydraulic performance of an airlift pump having a rectangular cross-section $20 \mathrm{~mm} \times 80 \mathrm{~mm}$ was investigated through an experimental program. The pump was operated at six different submergence ratios and the liquid flow rate was measured at various flowrates of air injected. The effectiveness of the pump, defined as the ratio of the mass of liquid pumped to the mass of air injected, was determined as a function of the mass of air injected for different submergence ratios. Results obtained were compared with those for circular airlift pumps using an analytical model for circular pumps. Effectiveness of the rectangular airlift pump was observed to be comparable to that of the circular pumps. Hydraulic performance of the rectangular airlift pump investigated was then described by a set of semilogarithmic empirical equations.
\end{abstract}

\section{Introduction}

Airlift pumps have been used since the beginning of the 20th century. They are simple devices in which liquid enters from one end, and a mixture of air and liquid discharges from the other end. Air is injected near the inlet. Almost without exception, the riser section of airlift pumps has been vertical pipes with circular cross-sections. As discussed by Parker [1], the air injector system for these pumps is in the form of an air jacket in which several small holes are drilled radially through the pipe and air is supplied to them from a surrounding manifold. Figure 1 shows the side view of the rectangular airlift pump used in this study. It is similar to pumps with circular section except that air is injected through a perforated pipe placed in the inlet section.

François et al. [2] have described the two-phase flow that takes place in the vertical section of the pump as (i) bubble flow that occurs when dispersed small air bubbles flow upward with the liquid; (ii) slug flow characterized by large air bubbles; (iii) churn flow which is similar to slug flow but with a more chaotic and disordered flow pattern; (iv) annular flow where the liquid phase flows upward as a film along the pipe wall, and the gas phase flows as a separate phase in the center of the pipe.

Initially, a detailed analysis of the flow in airlift pumps was not made for several decades. In general, the liquid flowrate in the pump was described by empirical correlations. It was known, however, by Pickert [3] that for each submergence ratio (ratio of the depth of the submerged portion of the pump, $H$, to the total pump height, $L$ ), the quantity of liquid pumped first increased rapidly with increased air consumption, then increased more slowly up to a maximum, after which it fell away.

The first published theoretical analysis of airlift pumps was presented by Gibson [4]. Gibson's study was followed by those of Pickert [3], Nicklin [5], Stenning and Martin [6], Parker [1], Clark and Dabolt [7], Sharma and Sachdeva [8], Morrison et al. [9], De Cachard and Delhaye [10], François et al. [2], Abed [11], Dare and Oturuhoyi [12], Pougatch and Salcudean [13], and Kassab et al. [14] among others. In all these studies, slug flow or its variations were assumed to take place in the pump.

Among the analytical models developed, Stenning and Martin's study has found wide acceptance since their study is well documented and the results are simple to use. Stenning and Martin [6] applied the momentum and energy balance equations to a circular airlift pump and their resulting equation is

$$
\frac{H}{L}-\frac{1}{\left[1+Q_{g} / s Q_{f}\right]}=\frac{V_{1}^{2}}{2 g L}\left[(K+1)+(K+2) \frac{Q_{g}}{Q_{f}}\right]
$$




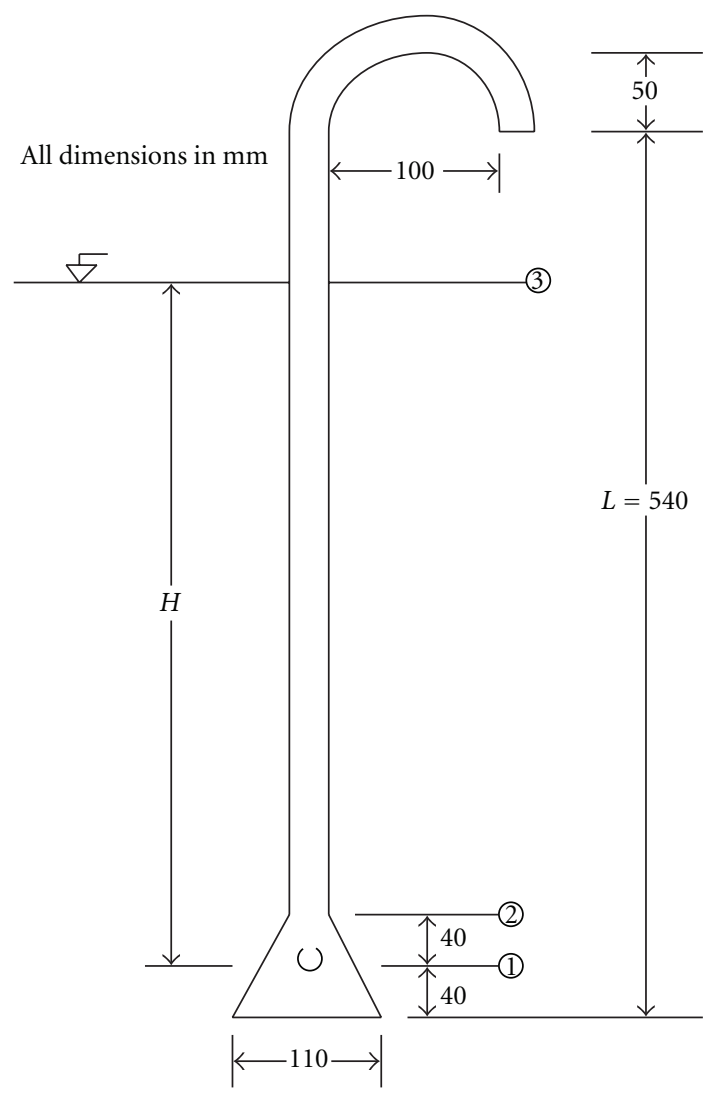

Figure 1: Model airlift pump with rectangular cross-section.

in which $Q_{g}$ is the air volume flowrate, $Q_{f}$ is the liquid volume flowrate, and $V_{1}$ is the velocity of the liquid at the pump inlet. The term $H / L$ is called the submergence ratio, and the other terms are defined as

$$
\begin{gathered}
K=\frac{4 f L}{D}, \\
s=\frac{V_{g}}{V_{f}}
\end{gathered}
$$

in which $K$ is referred to as the friction parameter, and $s$ as the slip ratio. Here, $f$ is the friction factor for the liquid alone flowing at its mean velocity in the riser, $D$ is the diameter of the pump, $V_{g}$ is the velocity of air, and $V_{f}$ is the velocity of the liquid. In deriving (1), Stenning and Martin [6] have assumed constant slip ratios.

Sharma and Sachdeva [8] have observed that when $Q_{f}$ is plotted against $\log Q_{g}$, that part of the curve in which pumps normally operate approximated to a straight line. Consequently, the following equation can be applied to the data in this region:

$$
Q_{f}=c^{\prime}+m^{\prime} \log _{10} Q_{g}
$$

in which $c^{\prime}$ and $m^{\prime}$ are experimental constants.
The efficiency of an airlift pump can be determined from the output work done by air lifting and the input work of the compressor which supplies air to the pump. The ideal power input can be determined by considering the isotropic or isentropic compression of air, and the pump output can be considered as the rate of work done in lifting the liquid through the pump height. However, several authors have defined the pump efficiency under different assumptions and a universally accepted expression for the efficiency is not available. As an alternative, Parker [1] has introduced the term effectiveness, $E$, which is defined as the ratio of the mass of liquid pumped to the mass of air injected.

In all these studies, the airlift pump investigated was a vertical pipe with a circular cross-section. In this study, performance of an airlift pump having a narrow rectangular cross-section will be reported. Rectangular airlift pumps have the additional advantage of providing a uniform flow field in pumping water or wastewater in various treatment units. For possible practical applications, the pump has to operate at low submergence and the footpiece design should be somewhat different than those used in circular pumps.

\section{Experimental Setup and Test Procedure}

The basic objective of the experimental program was to determine the water flowrate through the airlift pump for various air flowrates. The experimental setup for the airlift pump is shown in Figure 2. As can be seen, there is a closedcircuit water circulation system and a separate air supply system. The water circulation system consists of a pump sump, a weir tank, and a water storage tank. Water is pumped continuously between the water storage tank and the pump sump by a centrifugal pump at a rate slightly more than the pumping rate through the airlift pump. The excess flow is returned back to the storage tank through an adjustable overflow pipe placed in the pump sump. The overflow pipe also acts as a constant level device. This is necessary for the control of the submergence ratio. The airlift pump placed in the pump sump pumps water from the sump to the storage tank through a weir tank. The weir tank is equipped with a wave suppressor and a $30^{\circ}$ triangular weir.

The air supply system consists of control valves, a combination air filter and pressure regulator, water (in air) collector, a thermometer, and an air flow meter. Compressed air is supplied through a separate line connected to a central compressed air system.

The test program, entails experiments with a Plexiglas rectangular airlift pump of cross-section $20 \mathrm{~mm} \times 80 \mathrm{~mm}$. Air is supplied through a $10-\mathrm{mm}$ diameter diffuser pipe with eight 2-mm diameter holes drilled on top of the pipe. The diffuser pipe is placed parallel to the $80-\mathrm{mm}$ side of the inlet in the middle of a $40-\mathrm{mm}$ tapered section at the bottom of the pump. At the top of the pump, a semicircular section of $100 \mathrm{~mm}$ inside diameter is placed to ensure smooth flow of water into the weir tank. This short bend has been provided only for the easy collection of water and has negligible effect on the performance of the airlift pump. 


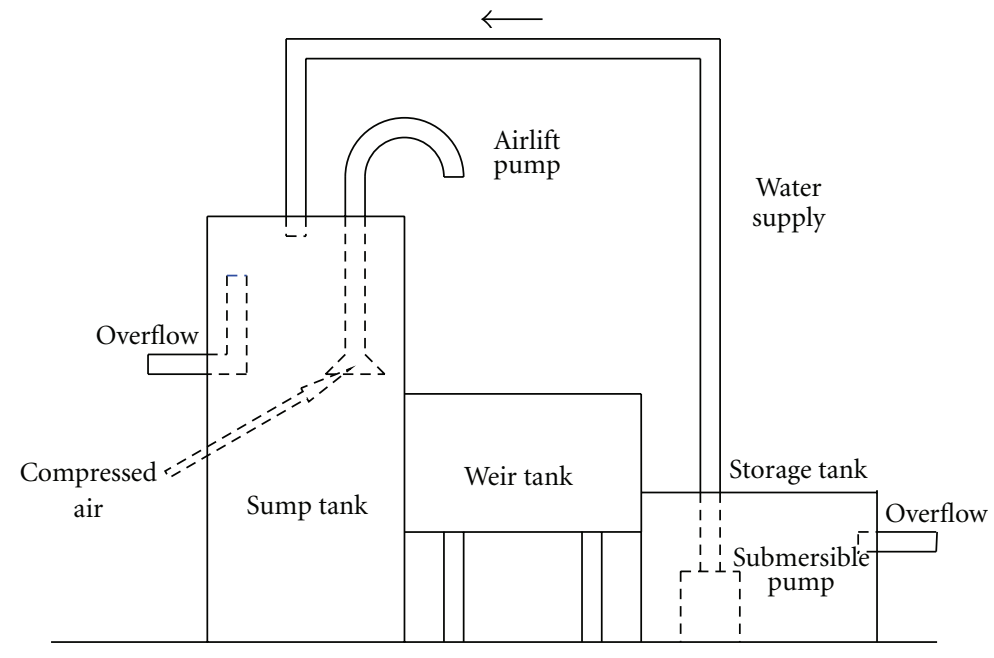

Figure 2: Experimental setup for the airlift pump.

One of the most important parameters that influence the performance of an airlift pump is the submergence ratio, that is, the ratio of the submerged portion, $H$, to the total vertical length of the pump, $L$. As can be seen in Figure 1, $L=540 \mathrm{~mm}$ is constant, and $H$ is varied to achieve different submergence ratios. In this study, for a fixed submergence ratio, the air flowrate was gradually increased from $3 \mathrm{l} / \mathrm{s}$ to the maximum available $18 \mathrm{l} / \mathrm{s}$ at small increments and the corresponding water flowrates were measured. The actual air flowrates were calculated by making appropriate pressure and temperature corrections. The experiments were repeated for submergence ratios of $0.226,0.339,0.452,0.565,0.678$, and 0.791 .

\section{Results and Discussion}

The flow pattern in a rectangular airlift pump can best be described as churn flow. The flow is disordered and large gas bubbles occur rather randomly. As opposed to annular flow in which the liquid film flows upward as a film along the pipe wall, some liquid in fact moves downward at the wall.

A suitable parameter that can be used for the comparison of the hydraulic performance of an airlift pump operating at different submergence ratios is the effectiveness, $E$, defined by Parker [1]. Figure 3 shows effectiveness, that is, the ratio of the mass of liquid pumped to that of the air injected plotted against mass flowrate of air at different submergence ratios. As expected, effectiveness increases with increasing submergence ratios. The effect of the submergence ratio is more pronounced at low mass flowrates of air.

To compare the effectiveness of a rectangular airlift pump with that of a circular pump, the effectiveness of a circular pump was calculated using the Stenning and Martin model given by (1). For that purpose, diameter of the circular pump was taken as $45 \mathrm{~mm}$, which gives almost the same crosssectional area as that of the rectangular area investigated. The slip ratio and the friction factor were assumed to be $s=3.0$ and $f=0.0081$, respectively, as given by Parker

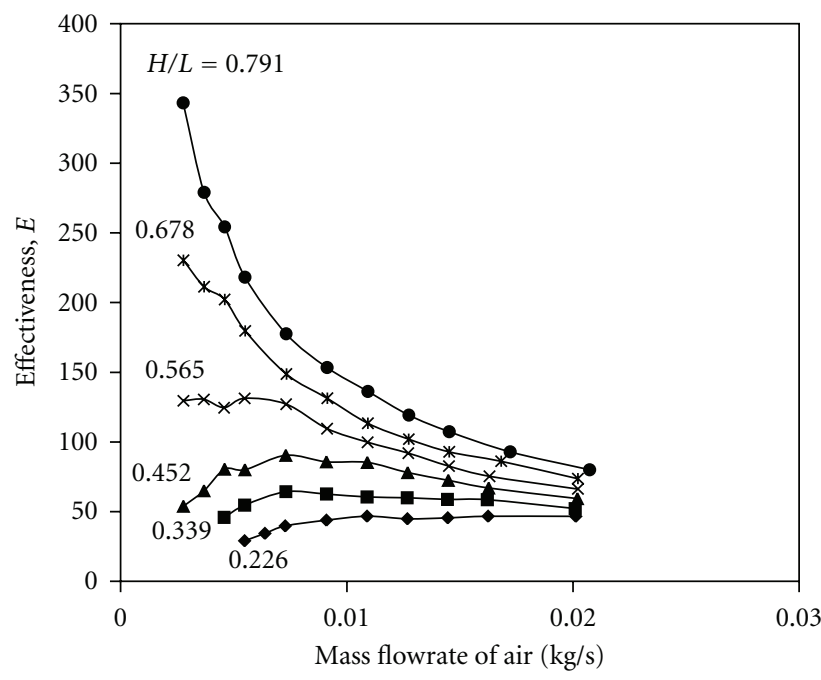

FIgURE 3: Effectiveness, $E$, as a function of the mass flowrate of air supplied at various submergence ratios.

[1]. The results are shown in Figure 4 for $H / L=0.565$, which is near the middle of the range of submergence ratios investigated. Contrary to expectations, the rectangular airlift pump performed better than the circular pump at large air flowrates. One reason for this might be the design of the air injection system where the vertical air jets have an increased momentum in the direction of flow, whereas the Stenning and Martin model was based on air-jacket type injectors. As discussed by Parker [1] and Khalil et al. [15], nozzle type air injection methods have also been used for circular airlift pumps in which air was supplied to a small nozzle chamber located on the center-line of the riser. When nozzle air injectors were used instead of air-jacket injectors in circular pumps, it was possible to increase the quantity of water pumped. Also, construction of a tapering inlet section is considered to have a positive effect. 


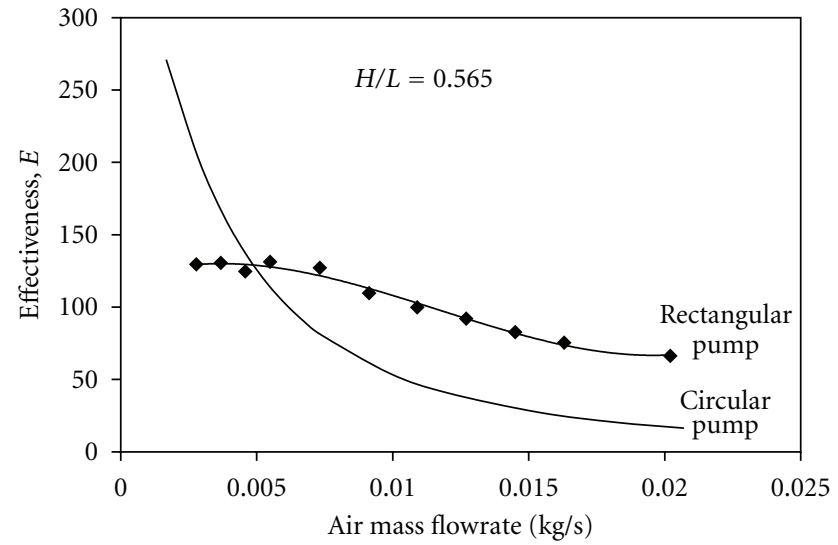

FIgURE 4: Comparison of the effectiveness, $E$, of circular and rectangular pumps at submergence ratio $H / L=0.565$.

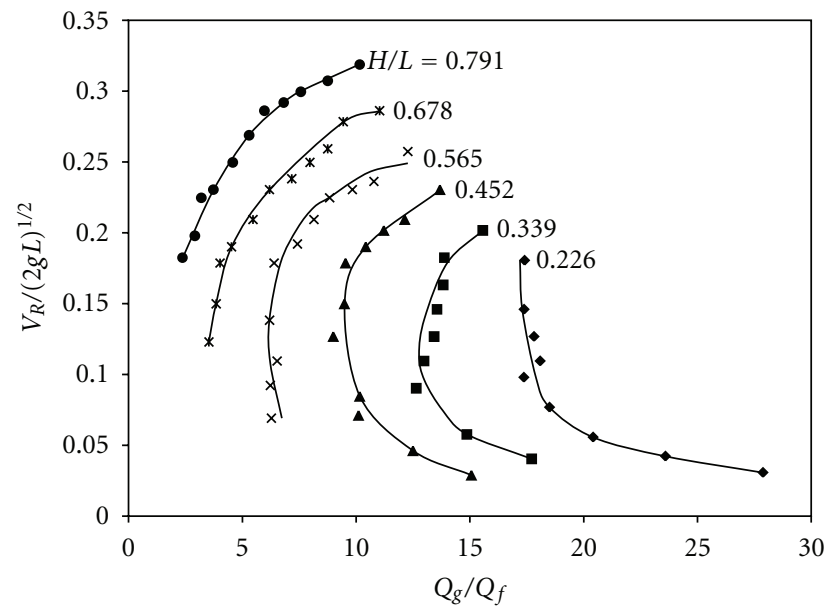

Figure 5: Variation of $V_{R} / \sqrt{2 g L}$ with $Q_{g} / Q_{f}$ at various submergence ratios.

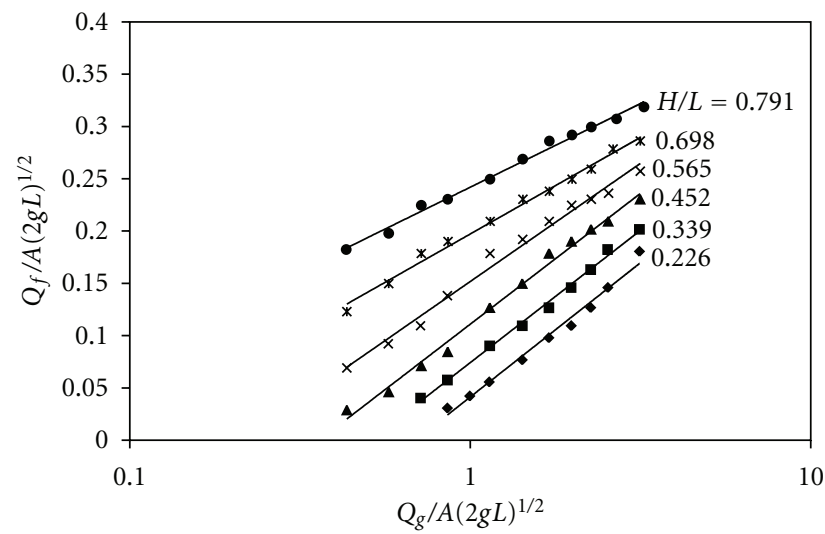

Figure 6: Variation of $Q_{f} / A \sqrt{2 g L}$ with $\log _{10} Q_{g} / A \sqrt{2 g L}$ at various submergence ratios.
TABLE 1: Least-squares estimates for the coefficients in (4).

\begin{tabular}{lcc}
\hline Submergence ratio, $H / L$ & $c$ & $m$ \\
\hline 0.226 & 0.0438 & 0.228 \\
0.339 & 0.0746 & 0.237 \\
0.452 & 0.1110 & 0.250 \\
0.565 & 0.1517 & 0.226 \\
0.678 & 0.1968 & 0.186 \\
0.791 & 0.2420 & 0.160 \\
\hline
\end{tabular}

The relationship given by (1) was plotted in terms of the dimensionless parameters $V_{1} / \sqrt{2 g L}$ against $Q_{g} / Q_{f}$ by Stenning and Martin [6]. Figure 5 shows a similar plot for the rectangular airlift pump investigated except that the velocity of liquid at the pump inlet, $V_{1}$, has been replaced by the velocity of liquid in the riser $V_{R}$. The results are similar to those for circular pipes.

Following the findings of Sharma and Sachdeva [8], a dimensionless plot of $Q_{f} / A \sqrt{2 g L}$ against the logarithm of $Q_{g} / A \sqrt{2 g L}$ was prepared for the rectangular airlift pump. This is shown in Figure 6 for each submergence ratio. The data plotted approximate to straight lines extremely well. Equation (3) can be rewritten in dimensionless form as

$$
\frac{Q_{f}}{A \sqrt{2 g L}}=c+m \log _{10} \frac{Q_{g}}{A \sqrt{2 g L}}
$$

in which $A$ is the cross-sectional area of the pump; $c$ and $m$ are experimental constants. The coefficients $c$ and $m$ were determined by least-squares analysis for each submergence ratio, and the results are tabulated in Table 1.

\section{Conclusions}

The following are concluded from this study: (i) rectangular airlift pump is a feasible alternative to the circular airlift pump; (ii) at this stage, pumps with different cross-sectional geometries should be investigated separately; (iii) effect of tapering air injector may enhance the performance of the airlift pump, and circular airlift pumps with similar air injectors should be investigated; (iv) empirical relationships of the form given by equation (4) represent the pump performance with reasonable accuracy.

\section{Acknowledgments}

This paper presents the results of the project "Performance of rectangular airlift pumps operating at low submergence" which was funded by Kuwait University Research Administration and Kuwait Foundation for the Advancement of Sciences under Grant no. EV 053/90-10-01. The author expresses his gratitude to both institutions for their support and encouragement. 


\section{References}

[1] G. J. Parker, "The effect of footpiece design on the performance of a small air lift pump," International Journal of Heat and Fluid Flow, vol. 2, no. 4, pp. 245-252, 1980.

[2] O. François, T. Gilmore, M. J. Pinto, and S. M. Gorelick, "A physically based model for air-lift pumping," Water Resources Research, vol. 32, no. 8, pp. 2383-2399, 1996.

[3] F. Pickert, "The theory of the air-lift pump," Engineering, vol. 34, pp. 19-20, 1932.

[4] A. H. Gibson, Hydraulics and Its Applications, Constable and Co., London, UK, 3rd edition, 1925.

[5] D. J.. Nicklin, "The air-lift pump: theory and optimisation," Transactions of the Institution of Chemical Engineers, vol. 41, pp. 29-39, 1963.

[6] A. H. Stenning and C. B. Martin, "An analytical and experimental study of air-lift pump performance," Journal of Engineering for Power-Transactions of the ASME A, vol. 90, no. 2, pp. 106-110, 1968.

[7] N. N. Clark and R. J. Dabolt, "A general design equation for air lift pumps operating in slug flow," AIChE Journal, vol. 32, no. 1 , pp. 56-64, 1986.

[8] N. D. Sharma and M. M. Sachdeva, "An air lift pump performance study," Journal of the Institution of Engineers, vol. 56, pp. 61-64, 1975.

[9] G. L. Morrison, T. I. Zeineddine, M. Henriksen, and G. B. Tatterson, "Experimental analysis of the mechanics of reverse circulation air lift pump," Industrial and Engineering Chemistry Research, vol. 26, no. 2, pp. 387-391, 1987.

[10] F. De Cachard and J. M. Delhaye, "A slug-churn flow model for small-diameter airlift pumps," International Journal of Multiphase Flow, vol. 22, no. 4, pp. 627-649, 1996.

[11] K. A. Abed, "Operational criteria of performance of air-lift pumps," Journal of the Institution of Engineers, vol. 84, no. 1, pp. 1-6, 2003.

[12] A. A. Dare and O. Oturuhoyi, "Experimental investigation of air lift pump," African Journal of Science and Technology, vol. 8, no. 1, pp. 56-62, 2007.

[13] K. Pougatch and M. Salcudean, "Numerical modelling of deep sea air-lift," Ocean Engineering, vol. 35, no. 11-12, pp. 11731182, 2008.

[14] S. Z. Kassab, H. A. Kandil, H. A. Warda, and W. H. Ahmed, "Air-lift pumps characteristics under two-phase flow conditions," International Journal of Heat and Fluid Flow, vol. 30, no. 1, pp. 88-98, 2009.

[15] M. F. Khalil, K. A. Elshorbagy, S. Z. Kassab, and R. I. Fahmy, "Effect of air injection method on the performance of an air lift pump," International Journal of Heat and Fluid Flow, vol. 20, no. 6, pp. 598-604, 1999. 

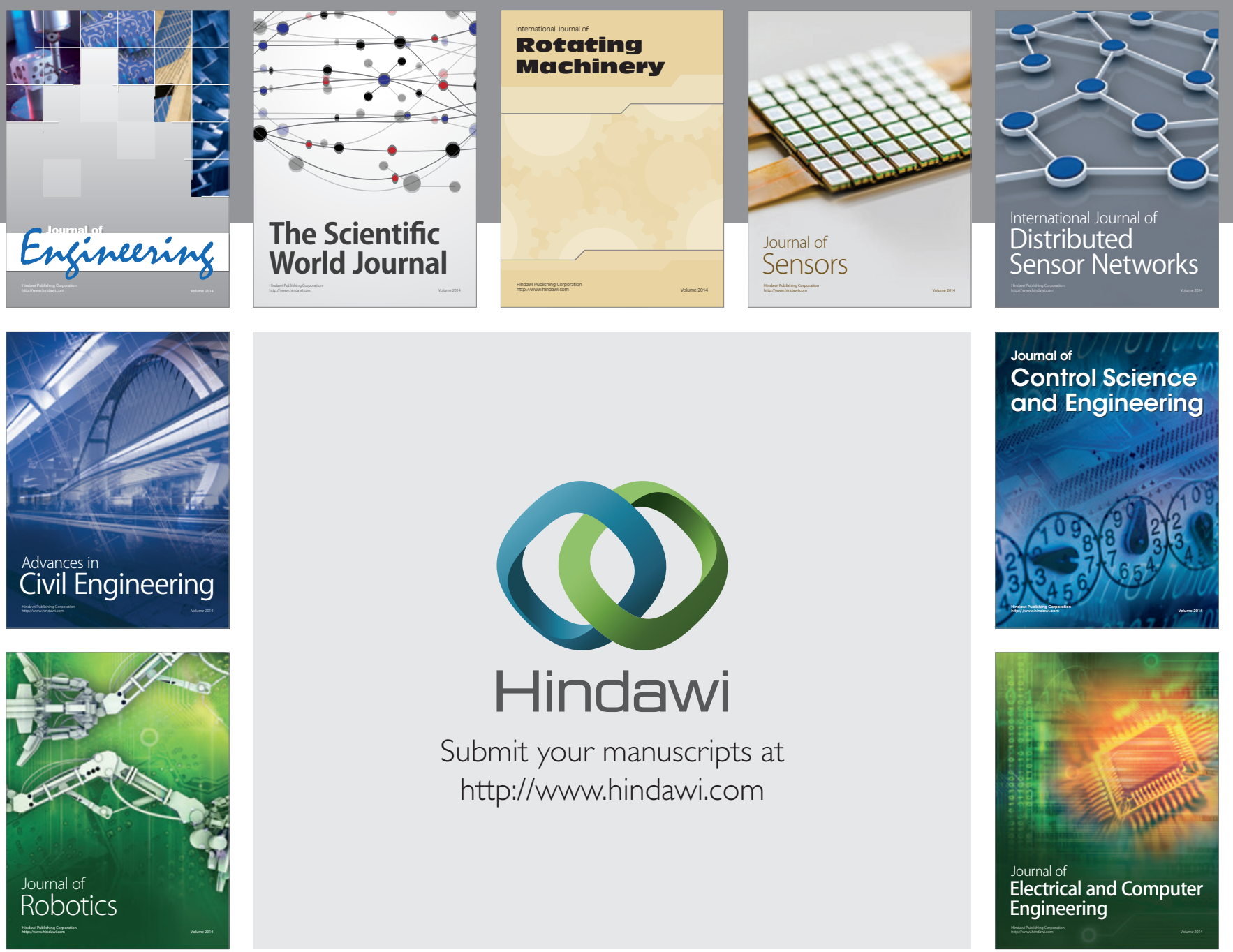

Submit your manuscripts at

http://www.hindawi.com
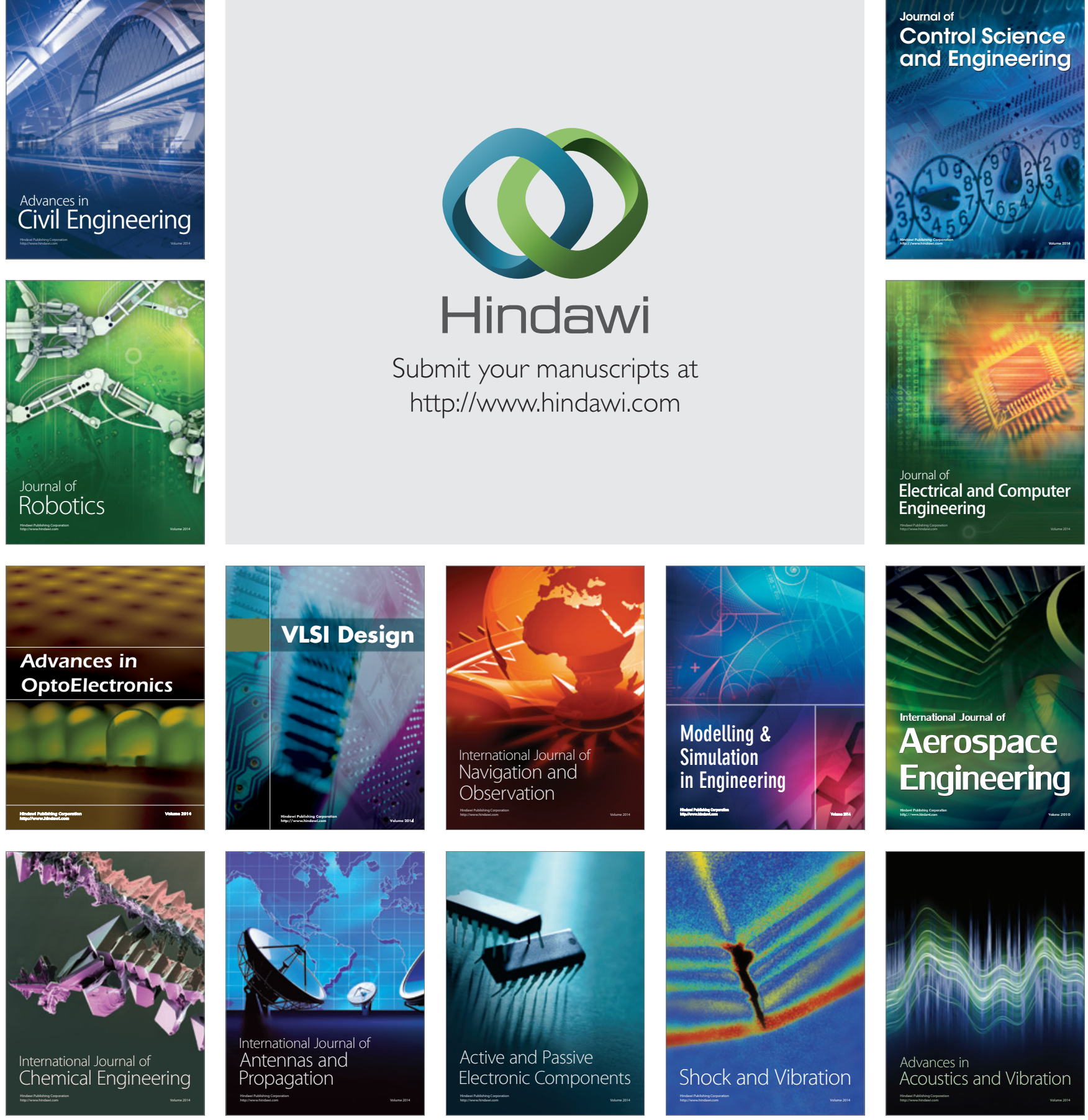